\title{
Comparison Matrix Method and Its Applications to Damage Evaluation for Existing Reinforced Concrete Bridges
}

\author{
Ming-Te Liang \\ mliang@mail.ntou.edu.tw \\ Chin-Ming Lin \\ 202. \\ Chi-Jang Yeh \\ Manager, Join Engineering Consultants, Taipei, Taiwan 100.
}

Professor, Department of Harbor and River Engineering, National Taiwan Ocean University, Keelung, Taiwan 202.,

Graduate Student, Department of Harbor and River Engineering, National Taiwan Ocean University, Keelung, Taiwan

Follow this and additional works at: https://jmstt.ntou.edu.tw/journal

Part of the Civil and Environmental Engineering Commons

\section{Recommended Citation}

Liang, Ming-Te; Lin, Chin-Ming; and Yeh, Chi-Jang (2003) "Comparison Matrix Method and Its Applications to Damage Evaluation for Existing Reinforced Concrete Bridges," Journal of Marine Science and Technology. Vol. 11: Iss. 2, Article 2.

DOI: $10.51400 / 2709-6998.2283$

Available at: https://jmstt.ntou.edu.tw/journal/vol11/iss2/2

This Research Article is brought to you for free and open access by Journal of Marine Science and Technology. It has been accepted for inclusion in Journal of Marine Science and Technology by an authorized editor of Journal of Marine Science and Technology. 


\section{Comparison Matrix Method and Its Applications to Damage Evaluation for Existing Reinforced Concrete Bridges}

Acknowledgements

The authors would like to thank the Join Engineering Consultants for its financial support of this study. 


\title{
COMPARISON MATRIX METHOD AND ITS APPLICATIONS TO DAMAGE EVALUATION FOR EXISTING REINFORCED CONCRETE BRIDGES
}

\author{
Ming-Te Liang*, Chin-Ming Lin**, and Chi-Jang Yeh***
}

Key words: analytic hierarchy process, visual inspection, weight allocation.

\section{ABSTRACT}

The main purpose of this paper was adopting the comparison matrix method, which is generated from both the analytic hierarchy process and the principle of moment equilibrium, to assess the repair order of existing reinforced concrete (RC) bridges. Ten existing RC bridges in Keelung, Taiwan, were given as an illustrative example. In order to verify the feasibility and reliability of the proposed method, the D (Degree) E (Extend) R (Relevancy) evaluation method, which is now widely used to evaluate the damage grade for existing RC bridges in Taiwan, was also applied to assessing the same ten existing $\mathrm{RC}$ bridges. The predicted results obtained from both the proposed and DER methods had the same repair order. The results presented in this study can be used as engineering decision-making for the repair, strengthening or demolition orders for existing RC bridges.

\section{INTRODUCTION}

Reinforced concrete (RC) bridges deteriorate with time occurred from material fatigue, environmental effects, and possible overloading. To secure safe and durable service, it is usual to perform periodic in-situ inspections. These inspections involve visual inspections, nondestructive methods, and partial destructive methods [2]. The data brought together from on-site inspections can be used to determine suitable repair, strengthening or demolition. Virtually, the exactness of the field measurement data is generally not good, and representatively has a high degree of uncertainty associated with it. For this explanation, it is being admitted that traditional deterministic methods [9] and

Paper Submitted 09/11/02, Accepted 05/30/03. Author for Correspondence: Ming-Te Liang.

*Professor, Department of Harbor and River Engineering, National Taiwan Ocean University, Keelung, Taiwan 202.E-mail:mliang@mail.ntou.edu. tw.

**Graduate Student, Department of Harbor and River Engineering, National Taiwan Ocean University, Keelung, Taiwan 202. ***Manager, Join Engineering Consultants, Taipei, Taiwan 100. probabilistic approaches $[10,20,22,24]$ are not always effective or efficient for bridge condition evaluation. Current research and development is increasingly employing structural health monitoring [3], vibration measurements and detection [7], neural network techniques $[23,27]$, wavelet analysis $[1,5,11]$, fuzzy logic and probability-based estimation $[8,25]$, fuzzy mathematics $[14,15,16]$ and gray theory $[13,17,18]$ for bridge condition evaluation.

The analytic hierarchy process (AHP) was developed by Saaty [21]. It is mainly applied to the decisionmaking problem with multiple evaluation criterions and uncertainty condition. The objective of AHP development is systematized to complicate problems. After hierarchical decomposition from different layers and through the quantitative judgment and seeking relations among them, the AHP is thus made a synthetic evaluation. This can provide that the decision-maker has full information to choose suitable plan. The risk of wrong decision-making is also decreased. The AHP is using eigenvalue method to find the weight of different items. Yang [28] adopted the eigenequation to construct the comparison matrix for finding the influenced weight and orders of multiple objectives to a objective and also employed this concept to find the priority development order in industry and agriculture. Chen [4] applied the comparison matrix method to the optimization problem of drainage basin plan. Yu and Cheng [29] provided an interactive comparison matrix approach for making group decision with multiple objectives. To date, however, no studies have attempt to evaluate the repair order for the existing RC bridges. This is a notable shortcoming, because the use of comparison matrix method in previous studies may be extensibly applied to the field of bridge management.

The objective of the present study was to determine the repair order of existing RC bridges. The ten existing RC bridges in Keelung, Taiwan, were given as an illustrative example. The present study results may be used as engineering reference for the repair, strengthening or demolition orders for existing RC bridges. 


\section{COMPARISON MATRIX METHOD}

Assume that the total weight of an item group, $B$, has 10. (The value of $B$ with 10 is not unique. The total weight of $B$ can be assumed as 1 , or 100 , or 1000 and so on.) The item group of $B$ consists of $C_{1}, C_{2}, \ldots$, and $C_{n}$ items. If the relative weight of comparing $C_{1}$ and $C_{i}(i$ $=1,2, . ., n)$ with $B$ is $C_{1 i}\left(0<C_{1 i}<10, i=1,2, \ldots, n\right)$, then

$$
C_{i 1}=10-C_{1 i}(\mathrm{i}=1,2, . ., n)
$$

If the given $C_{1}$ compared with two items $C_{i}$ and $C_{j}$ to $B$ have, respectively, weight $C_{1 i}$ and $C_{1 j}$, then $C_{i j}$ was the weight obtained from comparison $C_{i}$ and $C_{j}$ with $B$. The concept of this idea can be simulated as $C_{1 i}$ and $C_{1 j}$ forces separately act at two sides of a simple beam and has distance with 10 units as indicated in Fig. 1. Taking moment at $B$ point on the simple beam, we obtain

$$
C_{1 i} \times C_{i j}=\left(10-C_{i j}\right) \times C_{1 j}
$$

Therefore

$$
C_{i j}=\frac{10 \times C_{1 j}}{C_{1 i}+C_{1 j}}, \quad(i, j=1,2, \ldots, n ; i<j)
$$

From Eq. (1), we know

$$
C_{j i}+C_{i j}=10 \quad(i, j=1,2, \ldots, n)
$$

From Eq. (4), we obviously have

$$
C_{i i}=5 \quad(i=1,2, \ldots, n)
$$

Using Eqs. (1) to (5), we can construct comparison matrix and then evaluate weight, $\mathrm{W}$, as shown in Table 1. According to matrix theory, the corresponding eigenvalue is the relative weight of each factor in this layer to a factor on the upper layer [21]. Moreover, in Table 1, we had used

$$
\begin{aligned}
& M_{i}=\prod_{j=1}^{n} C_{i j} \quad(i, j=1,2, . ., n) \\
& \bar{W}_{i}=\sqrt[n]{M_{i}} \\
& W_{i}=\frac{\bar{W}_{i}}{\sum_{j=1}^{n} \bar{W}_{j}}
\end{aligned}
$$

Equation (7) is the geometric average value. Vector, $w=\left[w_{1}, w_{2}, \ldots, w_{n}\right]^{T}$, in which the superscript $T$ is the transposition of a matrix, is the eigenvector to be sought. Each factor $W_{1}, W_{2}, \ldots$, and $W_{n}$ is the relative weight of each item evaluation $C_{1}, C_{2}, \ldots$, and $C_{n}$ to $B$, respectively.

The relationship between the membership degrees, $R_{n, m}$, in which $(n=1,2, m=1,2 \ldots 21$ to be in tune with illustrative example as shown in the following) of each single factor evalution to evaluation index and weight, $\bar{W}_{n}$, is

$$
\bar{D}_{n}=\bar{W}_{n} \cdot R_{n, m}
$$

where the value of $\bar{D}_{n}$ in Eq. (9) is the fuzzy synthesis evaluation matrix. The purpose of $\bar{D}_{n}$ is reasonably constructing the membership function of each factor on evaluation set and the weight allocation of each factor.

Based on the fuzzy mathematic theory, the fuzzy synthesis evaluation result, $\bar{B}$, of any factor can be expressed as

$$
\bar{B}=\bar{A}_{n} \cdot \bar{D}_{n}
$$

where $\bar{A}_{n}$ is the weight vector evaluation by expert. The optimum repair order can be determined by using Eq. (10). The more the value of $B$ has, the better the priority selection to decision-making objective is.

\section{DER EVALUATION METHOD}

The DER evaluation method [6] involves separating bridge deterioration into $\mathrm{D}$ (degree), $\mathrm{E}$ (extend), $\mathrm{R}$ (relevancy) and U(urgency) for assessment. The major work of the DER evaluation method is visual inspection.

Table 1. Comparison matrix and relative weight

\begin{tabular}{cccccccc}
\hline $\mathrm{B}$ & $C_{1}$ & $C_{2}$ & $\cdots$ & $C_{n}$ & $M_{i}$ & $\bar{W}_{i}$ & $W_{i}$ \\
\hline$C_{1}$ & $C_{11}$ & $C_{12}$ & $\cdots$ & $C_{1 n}$ & $M_{1}$ & $\bar{W}_{1}$ & $W_{1}$ \\
$C_{2}$ & $C_{21}$ & $C_{22}$ & $\cdots$ & $C_{2 n}$ & $M_{2}$ & $\bar{W}_{2}$ & $W_{2}$ \\
$\bullet$ & $\bullet$ & $\bullet$ & & $\bullet$ & $\bullet$ & $\bullet$ & $\bullet$ \\
$\bullet$ & $\bullet$ & $\bullet$ & & $\bullet$ & $\bullet$ & $\bullet$ & $\bullet$ \\
$C_{n}$ & $C_{n 1}$ & $C_{n 2}$ & & $C_{n n}$ & $M_{n}$ & $\bar{W}_{n}$ & $W_{n}$ \\
\hline
\end{tabular}

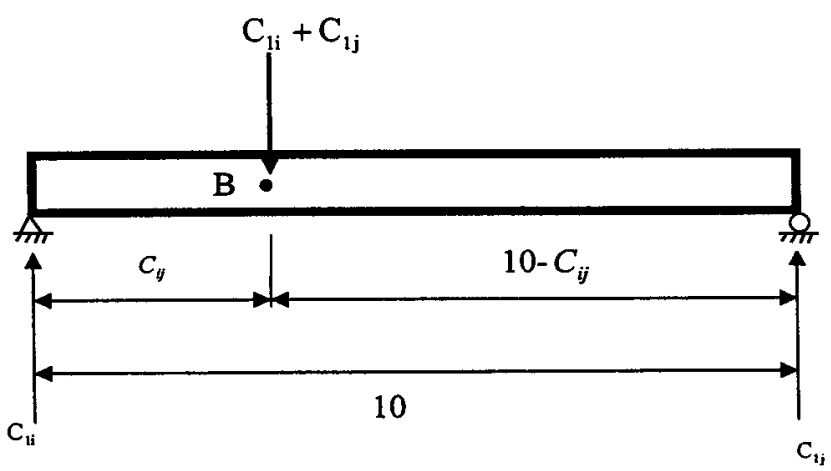

Fig. 1. $C_{1 j}$ and $C_{1 j}$ separately act at two sides of a simple beam. 
Table 2. Weight for each item of bridge in D.E.R. evaluation criterion

\begin{tabular}{lcllll}
\hline Item & Weight & Item & Weight Item & Weight \\
\hline Substructure protection $\left(C_{12}\right)$ & 6 & Minor member (diaphragm) $\left(C_{19}\right)$ & 6 & Abutment $\left(C_{6}\right)$ & 6 \\
Pier foundation $\left(C_{13}\right)$ & 8 & Deck or hinged plate $\left(C_{20}\right)$ & 7 & Wing masonry Retaining wall $\left(C_{7}\right)$ & 5 \\
Pier shaft $\left(C_{14}\right)$ & 7 & Guide passage Road embankment $\left(C_{1}\right)$ & 3 & Friction layer $\left(C_{8}\right)$ & 3 \\
Supporting mat $\left(C_{15}\right)$ & 5 & Guide passage Protection fence $\left(C_{2}\right)$ & 2 & Drainage appliance $\left(C_{9}\right)$ & 4 \\
Prevention earthquake block $\left(C_{16}\right)$ & 5 & River channel $\left(C_{3}\right)$ & 3 & Curb and pedestrian Way $\left(C_{10}\right)$ & 2 \\
Expansion joint $\left(C_{17}\right)$ & 6 & Guide passage Road embankment & 3 & Balustrade protection & 3 \\
& & protection $\left(C_{4}\right)$ & & Fence $\left(C_{11}\right)$ & \\
Major member (girder) $\left(C_{18}\right)$ & 8 & Abutment foundation $\left(C_{5}\right)$ & 6 & Other $\left(C_{21}\right)$ & \\
\hline
\end{tabular}

The assistant work was performed by using apparatus. The weight values corresponding to the assessment items in the DER evaluation method are listed in Table 2. The deterioration grade standard was divided into 4 levels. The assessment index of bridge situation is separated into CI (Condition Index), PI (Priority Index), FI (Functional Index) and OPI (Overall Priority Index). The calculation technique for each index is described as follows:

1. Condition Index (CI): Based on the visual inspection results of all bridge elements, the condition index is calculated by using

$$
C I=\frac{\sum\left(I c_{i} \times w_{i}\right)}{\sum w_{i}}
$$

where $w_{i}$ is the weight of each bridge item, the $w_{i}$ requirement is $w_{i} \geq 1$, and $I c_{i}$ is the condition index for each item and is calculated by using

$$
I c_{i}=\frac{\sum I c_{i i}}{n}
$$

in which $n$ is the number of relevant inspection items for a particular bridge, and $I c_{i i}$ is the subitem condition index for each item and is calculated as

$$
I c_{i i}=100-\frac{100 \times D \times E \times R^{a}}{b}
$$

in which $b=D_{\max } \times E_{\max } \times R_{\max }^{a}=4 \times 4 \times 4^{a}$ and $a=1$. The value for a can be set $a=2$ for an important bridge.

2. Priority Index (PI): The priority index is referred as the $I c_{i}$ item value which is the worst item in the bridge with lowest $I c_{i}$ value. The calculation step involves finding the minimum value for $I c_{i}$, i.e., $I c_{i}$ (min), from all assessment items. If the values for $I c_{i}$ (min) are less than 50 , between 50 and 75 , or between 75 and 100 , then choose the $I c_{i}$ value from this range as an average. The assessment items for the 12 th to $20^{\text {th }}$ are listed in Table 2 [6], The PI value is calculated by using

$$
P I=\frac{\sum_{i=12}^{i=20}\left(I c_{i} \times w_{i}\right)}{\sum_{i=12}^{i=20} w_{i}}
$$

3. Functional Index (FI): The functional index is calculated on the bridge construction sequence (CS), the actual bearing capacity (BC) per day, and the detour length (DL). The construction sequence is separated into the first, second and third grades, described as severe disaster, possibly occurring damage, and minimal destructive consequences, bridge has suffered damage, respectively. The bearing capacity of bridge is calculated by using

$$
B C=\frac{A D T}{C B W}
$$

where ADT stands for the average daily transportation and $\mathrm{CBW}$ stands for the complete bridge width. The maximum value for $B C$ is 200 .

The farther the detour length has, the more important the bridge is. The maximum value for DL is $20 \mathrm{~km}$. Based on the CS, BC, and DL values, the sc (serviceability coefficient) of the bridge can be determined and is divided into 12 classifications as shown in Fig. 2. The bridges falling into classification 1 are the most important to repair and those falling into classification 12 being the least important to repair. The FI value is calculated by using

$$
F I=\frac{100(s c-1)}{11}
$$

where the denominator (11) is used for normalization.

4. Overall Priority Index (OPI): The OPI value is evaluated by using

$$
O P I=w_{P} P I+w_{F} F I
$$

where $w_{P}$ and $w_{F}$ are the weights of PI and FI, 


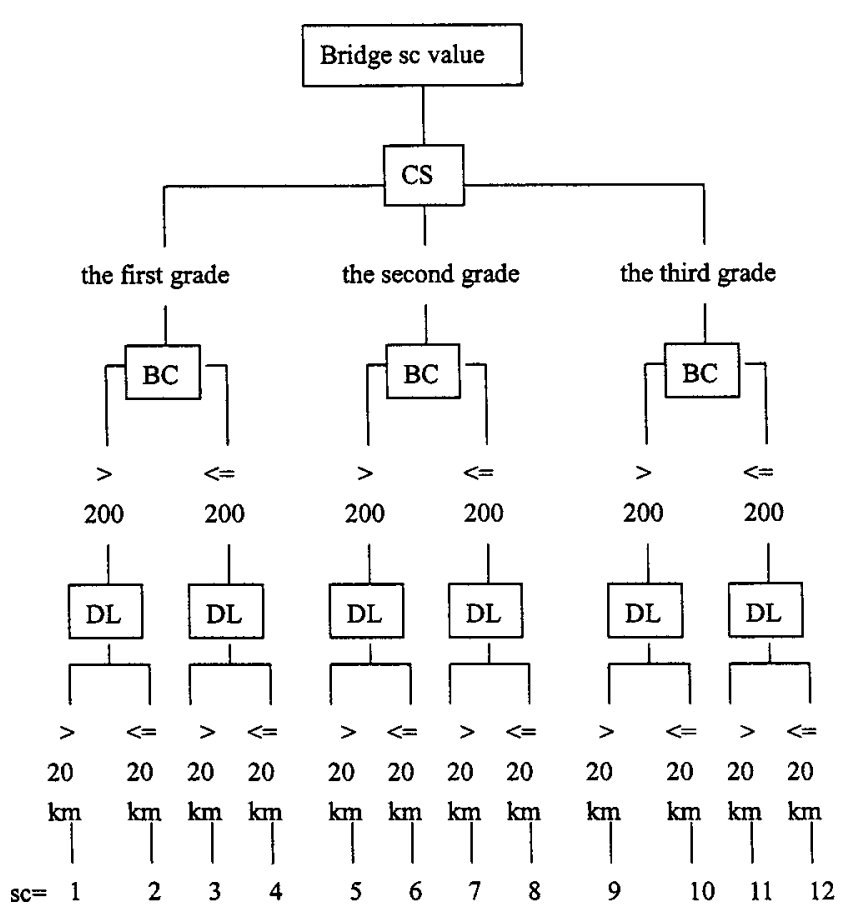

Fig. 2. Serviceability coefficient classifications.

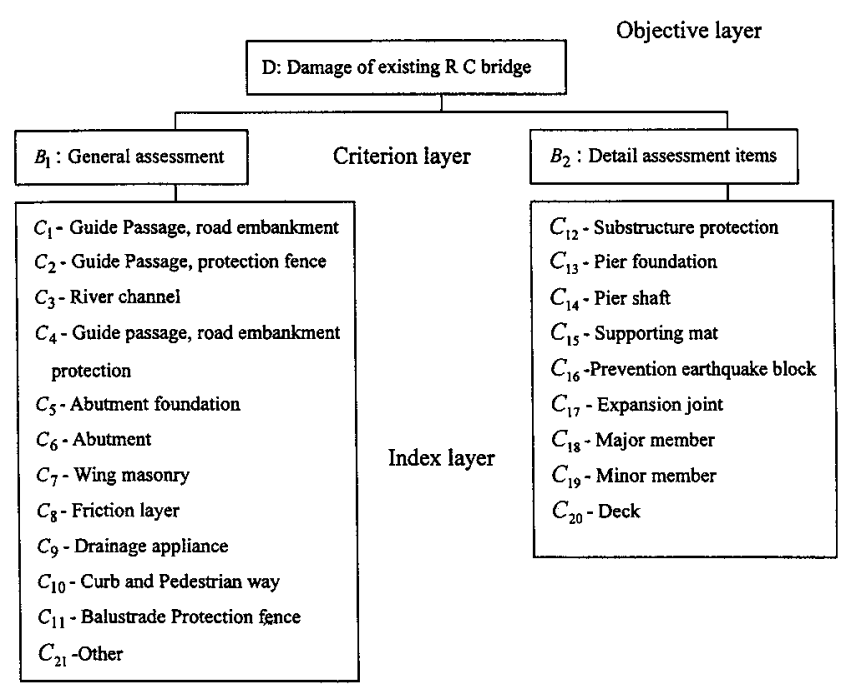

Fig. 3. Analytic hierarchy model for existing RC bridge.

respectively. $w_{P}+w_{F}=1, w_{P}=0.75$ and $w_{F}=0.25$.

Through the PI value, the entire situation for all bridges can be compared. According to the PI value for each bridge, bridge can be ranked from excellent to poor in series. This provides a reference for arranging the repair and strengthening order. This also supplies a suggested assessment for a repair urgency strategy due to a deteriorated bridge item.
Table 3. Weight of criterion layer $B$ with respect to objective layer D

\begin{tabular}{cccccc}
\hline $\mathrm{D}$ & $B_{1}$ & $B_{2}$ & $M_{i}$ & $\bar{W}_{i}$ & $W_{i}=\bar{A}_{n}$ \\
\hline$B_{1}$ & 5 & 1 & 5 & 2.236 & 0.25 \\
$B_{2}$ & 9 & 5 & 45 & 6.708 & 0.75 \\
& & & & 8.944 & \\
\hline
\end{tabular}

\section{ILLUSTRATIVE EXAMPLE}

We adopt the evaluated data of ten existing $\mathrm{RC}$ (Wuu-der, Long-men, Jong-jeng, Guan-in, Fuh-min, Dong-shyh, Shang-ren, Guang-hwa, Jong-her, Jongsan) bridges of Keelung city in Taiwan [12]. In order to use the comparison matrix method to evaluate these existing RC bridge, we first construct an analytic hierarchy model with three layers, i.e., objective layer D, criterion layer B and index layer $\mathrm{C}$ as shown in Fig. 3. After establishing this model, there is a set of expert evaluation vector between each single factor evaluation. This is for controlling the reliability of layer ranking. The combination of the expert evaluation vector to each single factor forms a comparison matrix and finds the corresponding weight vector.

\section{Comparison matrix D-B}

Based on the evaluated data of ten existing RC bridges stated above, the relative importance is first calculated by bridge experts. The comparison matrix is also to be constructed for finding the corresponding weight as indicated in Table 3. After calculating, we obtain the weight of criterion layer $B$ to objective layer D

$$
A_{B}^{T}=\left[\begin{array}{ll}
A_{B_{1}} & A_{B_{2}}
\end{array}\right]^{T}=\left[\begin{array}{ll}
0.25 & 0.75
\end{array}\right]^{T}
$$

\section{Comparison matrix $\mathrm{B}_{1}-\mathrm{C}$}

Let the 1-11 and 21 item single factor of the index layer $C$ perform comparison from bridge experts and form a comparison matrix as given in Table 4 . The corresponding weight of each single factor is

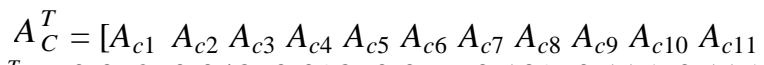
$\left.A_{c 21}\right]^{T}=\left[\begin{array}{lllllll}0.072 & 0.048 & 0.098 & 0.076 & 0.139 & 0.115 & 0.115\end{array}\right.$ $\left.\begin{array}{lllll}0.076 & 0.076 & 0.054 & 0.073 & 0.057\end{array}\right]^{T}$

$A_{C}^{T}$ mentioned above means the influenced importance of the general assessment items of index layer $\mathrm{C}$ to criterion layer $\mathrm{B}$.

\section{Comparison matrix $\mathbf{B}_{2}-\mathrm{C}$}

Let the 12-20 item single factor of the index layer 
Table 4. Weight of general assessment items

\begin{tabular}{cccccccccccccc}
\hline $\mathrm{B}_{1}$ & $\mathrm{C}_{1}$ & $\mathrm{C}_{2}$ & $\mathrm{C}_{3}$ & $\mathrm{C}_{4}$ & $\mathrm{C}_{5}$ & $\mathrm{C}_{6}$ & $\mathrm{C}_{7}$ & $\mathrm{C}_{8}$ & $\mathrm{C}_{9}$ & $\mathrm{C}_{10}$ & $\mathrm{C}_{11}$ & $\mathrm{C}_{21}$ & $W_{i}$ \\
\hline $\mathrm{C}_{1}$ & 5.00 & 9.00 & 3.00 & 5.00 & 1.00 & 2.00 & 2.00 & 5.00 & 5.00 & 8.00 & 5.00 & 8.00 & 0.072 \\
$\mathrm{C}_{2}$ & 1.00 & 5.00 & 2.50 & 3.57 & 1.00 & 1.82 & 1.82 & 3.57 & 3.57 & 4.71 & 3.57 & 4.71 & 0.048 \\
$\mathrm{C}_{3}$ & 7.00 & 7.50 & 5.00 & 6.25 & 2.50 & 4.00 & 4.00 & 6.25 & 6.25 & 7.27 & 6.25 & 7.27 & 0.098 \\
$\mathrm{C}_{4}$ & 5.00 & 6.43 & 3.75 & 5.00 & 1.67 & 2.86 & 2.86 & 5.00 & 5.00 & 6.15 & 5.00 & 6.15 & 0.076 \\
$\mathrm{C}_{5}$ & 9.00 & 9.00 & 7.50 & 8.33 & 5.00 & 6.67 & 6.67 & 8.33 & 8.33 & 8.89 & 8.33 & 8.89 & 0.139 \\
$\mathrm{C}_{6}$ & 8.00 & 8.18 & 6.00 & 7.14 & 3.33 & 5.00 & 5.00 & 7.14 & 7.14 & 8.00 & 7.14 & 8.00 & 0.115 \\
$\mathrm{C}_{7}$ & 8.00 & 8.18 & 6.00 & 7.14 & 3.33 & 5.00 & 5.00 & 7.14 & 7.14 & 8.00 & 7.14 & 8.00 & 0.115 \\
$\mathrm{C}_{8}$ & 5.00 & 6.43 & 3.75 & 5.00 & 1.67 & 2.86 & 2.86 & 5.00 & 5.00 & 6.15 & 5.00 & 6.15 & 0.076 \\
$\mathrm{C}_{9}$ & 5.00 & 6.43 & 3.75 & 5.00 & 1.67 & 2.86 & 2.86 & 5.00 & 5.00 & 6.15 & 5.00 & 6.15 & 0.076 \\
$\mathrm{C}_{10}$ & 2.00 & 5.29 & 2.73 & 3.85 & 1.11 & 2.00 & 2.00 & 3.85 & 3.85 & 5.00 & 3.85 & 5.00 & 0.054 \\
$\mathrm{C}_{11}$ & 5.00 & 6.43 & 3.75 & 5.00 & 1.67 & 2.86 & 2.86 & 5.00 & 5.00 & 6.15 & 5.00 & 3.85 & 0.073 \\
$\mathrm{C}_{21}$ & 2.00 & 5.29 & 2.73 & 3.85 & 1.11 & 2.00 & 2.00 & 3.85 & 3.85 & 5.00 & 6.15 & 5.00 & 0.057 \\
\hline
\end{tabular}

Table 5. Weight of detail assessment items

\begin{tabular}{ccccccccccc}
\hline $\mathrm{B}_{2}$ & $\mathrm{C}_{12}$ & $\mathrm{C}_{13}$ & $\mathrm{C}_{14}$ & $\mathrm{C}_{15}$ & $\mathrm{C}_{16}$ & $\mathrm{C}_{17}$ & $\mathrm{C}_{18}$ & $\mathrm{C}_{19}$ & $\mathrm{C}_{20}$ & $W_{i}$ \\
\hline $\mathrm{C}_{12}$ & 5.00 & 3.00 & 3.00 & 4.00 & 6.00 & 5.00 & 3.00 & 5.00 & 4.00 & 0.100 \\
$\mathrm{C}_{13}$ & 7.00 & 5.00 & 5.38 & 6.37 & 6.37 & 5.83 & 5.00 & 5.83 & 5.83 & 0.131 \\
$\mathrm{C}_{14}$ & 7.00 & 4.62 & 5.00 & 6.00 & 6.00 & 5.45 & 4.62 & 5.45 & 5.00 & 0.120 \\
$\mathrm{C}_{15}$ & 6.00 & 3.63 & 4.00 & 5.00 & 5.00 & 4.44 & 3.64 & 4.44 & 4.00 & 0.095 \\
$\mathrm{C}_{16}$ & 4.00 & 3.63 & 4.00 & 5.00 & 5.00 & 4.44 & 3.64 & 4.44 & 4.00 & 0.095 \\
$\mathrm{C}_{17}$ & 5.00 & 4.17 & 4.55 & 5.56 & 5.56 & 5.00 & 4.17 & 5.00 & 4.55 & 0.108 \\
$\mathrm{C}_{18}$ & 7.00 & 5.00 & 5.38 & 6.36 & 6.36 & 5.83 & 5.00 & 5.83 & 5.83 & 0.131 \\
$\mathrm{C}_{19}$ & 5.00 & 4.17 & 4.55 & 5.56 & 5.56 & 5.00 & 4.17 & 5.00 & 4.55 & 0.108 \\
$\mathrm{C}_{20}$ & 6.00 & 4.62 & 5.00 & 6.00 & 6.00 & 5.45 & 4.62 & 5.45 & 5.00 & 0.120 \\
\hline
\end{tabular}

$C$ carry out comparison from bridge experts and construct a comparison matrix as indicated in Table 5. The corresponding weight of each single factor is

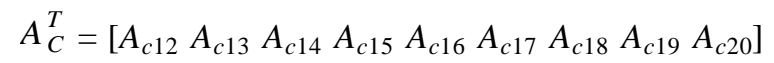
${ }^{T}=\left[\begin{array}{llllllll}0.100 & 0.131 & 0.120 & 0.095 & 0.095 & 0.108 & 0.131 & 0 .\end{array}\right.$ $\left.1080^{0.120}\right]^{T}$

$A_{C}^{T}$ stated above means the influenced importance of the detail assessment items of index layer $C$ to criterion layer $B$.

\section{Fuzzy synthesis evaluation}

The weight vectors, $A_{C}^{T}$, of the general and detail assessment items of criterion layer $B$ have been calculated. The values of $A_{C}^{T}$ will influence the change of repair order of existing RC bridge of evaluation factor to total objective layer. Table 6 shows the DER values of each composite member for the Jong-san bridge in Keelung, Taiwan. The DER values of each composite member for the other bridges are shown in reference [12]. The estimation index for each bridge was obtained from the product of each DER value (i.e., $D \times E \times R)$ and is expressed in Table 7. The maximum and minimum membership function in fuzzy mathematics suggested by Zadeh [30] are adopted and expressed as in the following:

$$
\mu(x)=\left\{\begin{array}{cc}
1 & f(x) \leq \inf (f) \\
\frac{\sup (f)-f(x)}{\sup (f)-\inf (f)} & \inf (f)<f(x)<\sup (f) \\
0 & f(x) \geq \sup (f)
\end{array}\right.
$$

and

$$
\mu(x)=\left\{\begin{array}{cc}
1 & f(x) \geq \inf (f) \\
\frac{f(x)-\inf (f)}{\sup (f)-\inf (f)} & \inf (f)<f(x)<\sup (f) \\
0 & f(x) \leq \sup (f)
\end{array}\right.
$$

where $\sup (f)$ and $\inf (f)$ are the supremum and infimum 
Table 6. Each composite member D.E.R. value for the Jong-san bridge in Keelung, Taiwan

\begin{tabular}{|c|c|c|c|c|c|c|c|c|c|c|c|}
\hline \multicolumn{4}{|c|}{ Bridge name: Jong-san bridge } & \multicolumn{8}{|c|}{ Bridge No.: Assessment date: 1999 / 08 / 18} \\
\hline \multicolumn{12}{|c|}{ General assessment items } \\
\hline Assessment items & $\mathrm{D}$ & $\mathrm{E}$ & $\mathrm{R}$ & Assessment items & $\mathrm{D}$ & $\mathrm{E}$ & $\mathrm{R}$ & Assessment items & $\mathrm{D}$ & $\overline{\mathrm{E}}$ & $\mathrm{R}$ \\
\hline \multirow{4}{*}{$\begin{array}{l}\text { 1.Guide passage } \\
\text { road embankment } \\
\text { 2.Guide passage } \\
\text { protection fence } \\
\text { 3. River channel } \\
\text { 4.Guide passage } \\
\text { road embankment } \\
\text { protection }\end{array}$} & 1 & & & 5.Abutment & 0 & & & 9.Drainage appliance & 1 & & \\
\hline & 1 & & & $\begin{array}{l}\text { foundation } \\
6 \text {. Abutment }\end{array}$ & 2 & 3 & 2 & $\begin{array}{l}\text { 10.Stone curb and } \\
\text { Pedestrian way }\end{array}$ & 1 & & \\
\hline & & & & 7.Wing masonry & 2 & 3 & 2 & 11.Balustrade protection & 1 & & \\
\hline & $\begin{array}{l}0 \\
2\end{array}$ & 3 & 3 & 8.Friction layer & 1 & & & $\begin{array}{l}\text { fence } \\
21 . \text { Other }\end{array}$ & 1 & & \\
\hline
\end{tabular}

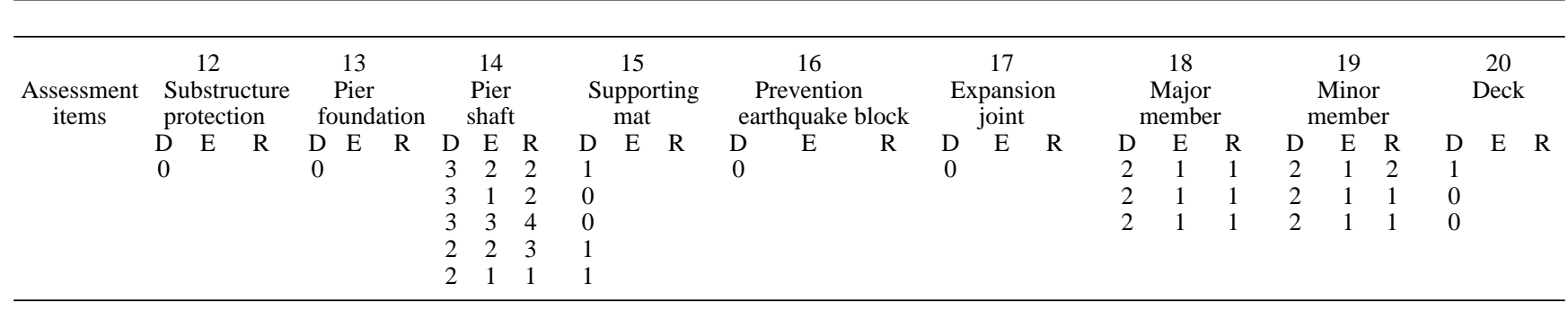

N/A Without this itemU/I unable to assessR/U unable to judge relative importance

\begin{tabular}{|c|c|c|c|c|c|c|c|c|c|c|c|c|c|c|c|c|}
\hline \multicolumn{4}{|c|}{ Assessment grade D } & & \multicolumn{4}{|c|}{ Range E } & \multicolumn{5}{|c|}{ Importance R with respect to bridge } & \multicolumn{3}{|c|}{ Emergency } \\
\hline N/A Good & Mediate & Poor & Severe & & $\mathrm{U} / \mathrm{I}$ & Local & & Global & R/U small & & & Large & Rout & 5 years & lyear & urgency \\
\hline $0 \quad 1$ & 2 & 3 & 4 & 0 & 1 & 2 & 3 & 4 & 0 & 2 & 3 & 4 & 0 & 1 & 2 & 34 \\
\hline
\end{tabular}

Table 7. Bridge system estimation criterion and index obtained from $D \times E \times R$

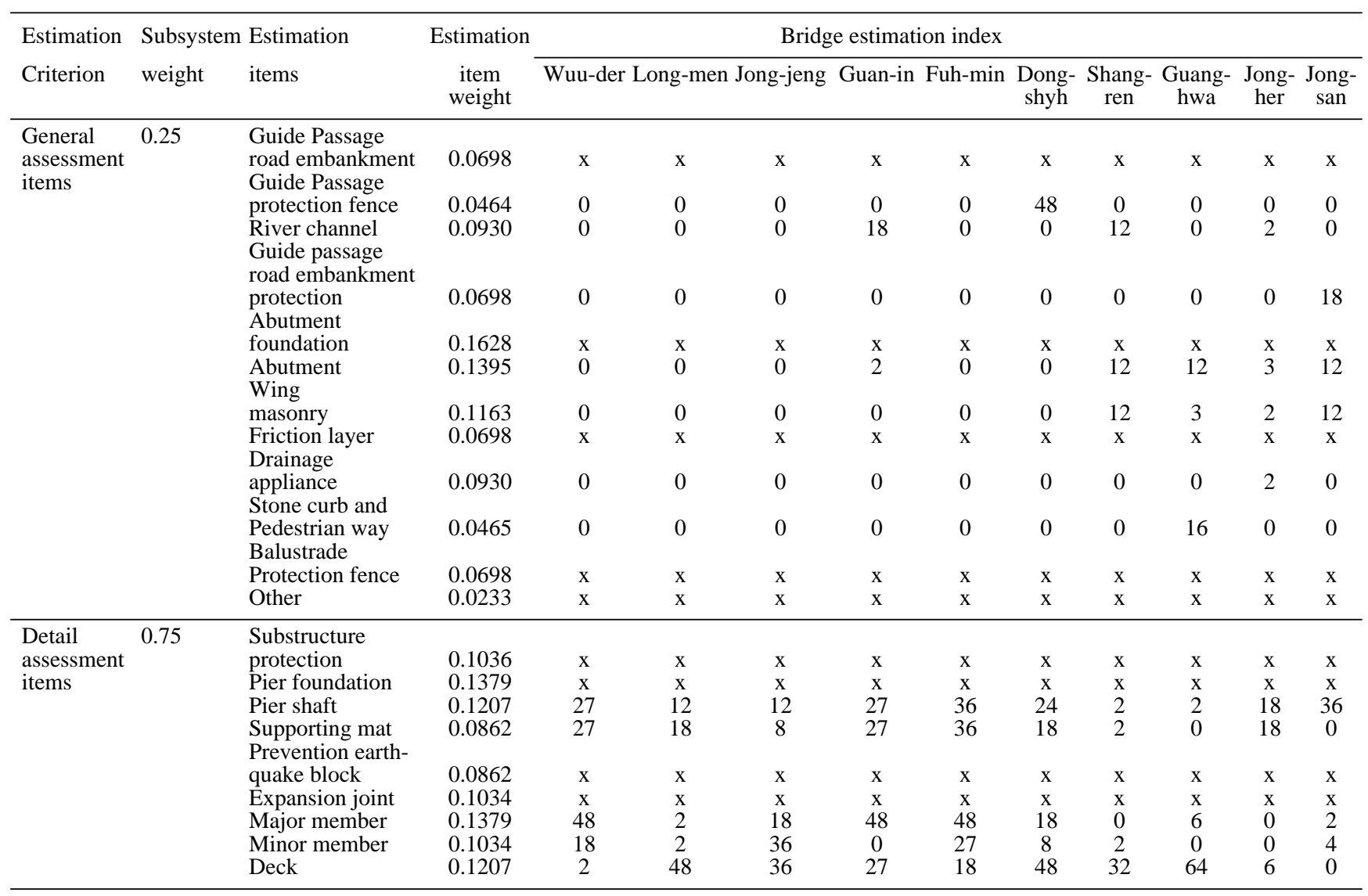


of $f(x)$, respectively. It is understandable that Eq. (18) is a membership function with monotonic decrease whereas Eq (19) is a membership function with monotonic increase. The meaning of Eq. (18) is that the less the value is the better the need to employer does. The significance of Eq. (19) is just the opposite of Eq. (18). The higher the value is, the better the need of benefit effect to employer does. Using the estimation index of each composte member DER values and adopting Eq. (19), the membership degree, $R_{n, m}(n=1,2 m=1,2 \ldots$, 21 ), of each single factor estimation to estimation index to 21 items of bridge can be calculated as follows:

For general assessment items $\left(R_{n, m}, n=1, m=1\right.$, $2 \ldots, 11,21)$ :

$$
\begin{aligned}
& R_{1,1}=[\times \times \times \times \times \times \times \times] \\
& R_{1,2}=\left[\begin{array}{llllllllll}
0 & 0 & 0 & 0 & 0 & 0 & 0 & 0 & 0 & 0
\end{array}\right] \\
& R_{1,3}=\left[\begin{array}{llllllllll}
0 & 0 & 0 & 1 & 0 & 0 & 0.67 & 0 & 0.11 & 0
\end{array}\right] \\
& R_{1,4}=\left[\begin{array}{llllllllll}
0 & 0 & 0 & 0 & 0 & 0 & 0 & 0 & 0 & 0
\end{array}\right] \\
& R_{1,5}=[\times \times \times \times \times \times \times \times] \\
& R_{1,6}=\left[\begin{array}{llllllllll}
0 & 0 & 0 & 0.17 & 0 & 0 & 1 & 1 & 0.25 & 1
\end{array}\right] \\
& R_{1,7}=\left[\begin{array}{llllllllll}
0 & 0 & 0 & 0 & 0 & 0 & 1 & 0.25 & 0.17 & 1
\end{array}\right] \\
& R_{1,8}=[\times \times \times \times \times \times \times \times \times] \\
& R_{1,9}=\left[\begin{array}{llllllllll}
0 & 0 & 0 & 0 & 0 & 0 & 0 & 0 & 1 & 0
\end{array}\right] \\
& R_{1,10}=\left[\begin{array}{llllllllll}
0 & 0 & 0 & 0 & 0 & 0 & 0 & 1 & 0 & 0
\end{array}\right] \\
& R_{1,11}=[\times \times \times \times \times \times \times \times] \\
& R_{1,21}=[\times \times \times \times \times \times \times \times \times]
\end{aligned}
$$

where $\times$ denotes that the membership degree can not be calculated due to non-assessment.

For detail assessment items $\left(R_{n, m}, n=2, m=12\right.$, $13, \ldots, 20)$ :

$$
\begin{aligned}
& R_{2,12}=\left[\begin{array}{llllll}
\times \times \times \times \times \times \times \times & \times
\end{array}\right] \\
& R_{2,13}=\left[\begin{array}{llllllllll}
\times \times \times \times \times \times \times \times \times & \times
\end{array}\right] \\
& R_{2,14}=\left[\begin{array}{llllllllll}
0.74 & 0.29 & 0.29 & 0.74 & 1 & 0.65 & 0 & 0 & 0.47 & 1
\end{array}\right] \\
& R_{2,15}=\left[\begin{array}{lllllllll}
0.75 & 0.50 & 0.22 & 0.75 & 1 & 0.50 & 0.06 & 0
\end{array}\right.
\end{aligned}
$$
$0.51]$

$$
R_{2,16}=[\times \times \times \times \times \times \times \times]
$$

$$
\begin{aligned}
& R_{2,17}=\left[\begin{array}{llllllllll}
\times & \times & \times & \times & \times & \times & \times
\end{array}\right] \\
& R_{2,18}=\left[\begin{array}{llllllllll}
1 & 0.04 & 0.38 & 1 & 1 & 0.38 & 0 & 0.13 & 0 & 0.04
\end{array}\right] \\
& R_{2,19}=\left[\begin{array}{llllllllll}
0.50 & 0.06 & 1 & 0 & 0.75 & 0.22 & 0.06 & 0 & 0 & 0.11
\end{array}\right] \\
& R_{2,20}=\left[\begin{array}{llllllllll}
0.03 & 0.75 & 0.56 & 0.42 & 0.28 & 0.75 & 0.50 & 1
\end{array}\right.
\end{aligned}
$$
$0.090]$

Both the general and detail assessment items, $R_{1, m}$ ( $n=1, m=1,2 \ldots, 11,21)$ and $R_{1, m}(n=2, m=12,13$, ..., 20) mentioned above, can be respectively expressed in terms of matrix form as follows

$$
\left\lfloor R_{1, m} \mid=\left[\begin{array}{cccccccccc}
0 & 0 & 0 & 0 & 0 & 0 & 0 & 0 & 0 & 0 \\
0 & 0 & 0 & 0 & 0 & 1 & 0 & 0 & 0 & 0 \\
0 & 0 & 0 & 1 & 0 & 0 & 0.67 & 0 & 0.11 & 0 \\
0 & 0 & 0 & 0 & 0 & 0 & 0 & 0 & 0 & 0 \\
0 & 0 & 0 & 0 & 0 & 0 & 0 & 0 & 0 & 0 \\
0 & 0 & 0 & 0.17 & 0 & 0 & 1 & 1 & 0.25 & 1 \\
0 & 0 & 0 & 0 & 0 & 0 & 1 & 0.25 & 0.17 & 1 \\
0 & 0 & 0 & 0 & 0 & 0 & 0 & 0 & 0 & 0 \\
0 & 0 & 0 & 0 & 0 & 0 & 0 & 0 & 1 & 0 \\
0 & 0 & 0 & 0 & 0 & 0 & 0 & 1 & 0 & 0 \\
0 & 0 & 0 & 0 & 0 & 0 & 0 & 0 & 0 & 0 \\
0 & 0 & 0 & 0 & 0 & 0 & 0 & 0 & 0 & 0
\end{array}\right]\right.
$$

and

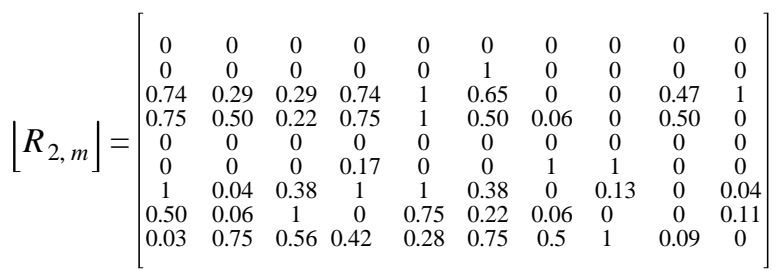

The weights, $\bar{W}_{n}(n=1,2)$, of each bridge item have been calculated by the comparison matrix method as shown in Tables 4 and 5 and been listed below, respectively,

$\bar{W}_{1}=\left[\begin{array}{llllll}0.072 & 0.048 & 0.098 & 0.076 & 0.139 & 0.115\end{array}\right.$ $\left.\begin{array}{llllll}0.115 & 0.076 & 0.076 & 0.054 & 0.073 & 0.057\end{array}\right]$

and

$$
\bar{W}_{2}=\left[\begin{array}{llllll}
0.100 & 0.131 & 0.120 & 0.095 & 0.095 & 0.102
\end{array}\right.
$$
$\left.\begin{array}{lll}0.131 & 0.103 & 0.120\end{array}\right]$

According to Eq. (9), we have, respectively,

$$
\bar{D}_{1}=\left[\begin{array}{lllllllll}
0 & 0 & 0 & 0.118 & 0 & 0.048 & 0.297 & 0.198 & 0.135
\end{array}\right.
$$
$0.306]$

and 
Table 8. Weight for each item of bridge obtained from comparison matrix method (Case I)

\begin{tabular}{|c|c|c|c|c|c|}
\hline Item & Weight & Item & Weight & Item & Weight \\
\hline Substructure protection & 0.1002 & Minor element & & Abutment $\left(\mathrm{C}_{6}\right)$ & 0.1516 \\
\hline$\left(\mathrm{C}_{12}\right)$ & & $\left(\right.$ diaphragm) $\left(\mathrm{C}_{19}\right)$ & 0.1000 & Wing masonry/ & \\
\hline Pier foundation $\left(\mathrm{C}_{13}\right)$ & 0.1501 & Deck or hinged plate $\left(\mathrm{C}_{20}\right)$ & 0.1332 & retaining wall $\left(\mathrm{C}_{7}\right)$ & 0.1300 \\
\hline Pier shaft $\left(\mathrm{C}_{14}\right)$ & 0.1332 & Guide passage $\left(C_{1}\right)$ & 0.0867 & Friction layer $\left(\mathrm{C}_{8}\right)$ & 0.0433 \\
\hline Supporting mat $\left(\mathrm{C}_{15}\right)$ & 0.0666 & Road embankment & & Drainage appliance $\left(\mathrm{C}_{9}\right)$ & 0.1083 \\
\hline Shear key/ & & Guide passage $\left(\mathrm{C}_{2}\right)$ & 0.0216 & & \\
\hline Restrained cable $\left(\mathrm{C}_{16}\right)$ & 0.0666 & Protection fence & & Curb and pedestrian & \\
\hline Expansion joint $\left(\mathrm{C}_{17}\right)$ & 0.1000 & River channel $\left(\mathrm{C}_{3}\right)$ & 0.1121 & Way $\left(\mathrm{C}_{10}\right)$ & 0.0216 \\
\hline \multirow[t]{3}{*}{ Major element (girder) } & 0.1501 & Guide passage $\left(\mathrm{C}_{4}\right)$ & 0.0867 & Balustrade/ & \\
\hline & & road embankment protection & & Protection fence $\left(\mathrm{C}_{11}\right)$ & 0.0433 \\
\hline & & Abutment foundation $\left(\mathrm{C}_{5}\right)$ & 0.1732 & Other $\left(\mathrm{C}_{21}\right)$ & 0.0216 \\
\hline
\end{tabular}

$\bar{D}_{2}=\left[\begin{array}{llllll}0.349 & 0.134 & 0.281 & 0.341 & 0.461 & 0.289\end{array}\right.$ $\begin{array}{llll}0.072 & 0.370 & 0.145 & 0.137]\end{array}$

Let $\bar{D}_{1}$ and $\bar{D}_{2}$ be represented by the fuzzy synthesis estimation matrix. We have

$$
\begin{aligned}
& \bar{D}_{n}=\left[\begin{array}{ll}
\bar{D}_{1} & \bar{D}_{2}
\end{array}\right]^{T}=\left[\begin{array}{l}
\bar{D}_{1} \\
\bar{D}_{2}
\end{array}\right] \\
& \bar{D}_{n}=\left[\begin{array}{cccccccccc}
0 & 0 & 0 & 0.118 & 0 & 0.048 & 0.297 & 0.198 & 0.135 & 0.306 \\
0.349 & 0.134 & 0.281 & 0.341 & 0.461 & 0.289 & 0.072 & 0.370 & 0.145 & 0.137
\end{array}\right]
\end{aligned}
$$

From Table 3, we have the weight of criterion layer $B$ with respect to objective layer $D$

$$
\bar{A}_{n}^{T}=\left[\begin{array}{ll}
0.25 & 0.75
\end{array}\right]
$$

Substituting the values of $\bar{D}_{n}$ and $\bar{A}_{n}$ into Eq. (10), we obtain the membership degree of fuzzy synthesis evaluation result

$$
\bar{B}=\left[\begin{array}{llllll}
0.262 & 0.138 & 0.211 & 0.286 & 0.345 & 0.229
\end{array}\right.
$$

\section{$0.128 \quad 0.152 \quad 0.120 \quad 0.179]$}

$=[$ Wuu-der, Long-men, Jong-jeng, Guan-in, Fuhmin, Dong-shyh, Shang-ren, Guang-hwa, Jong-her, Jongsan]

The greater the membership degree is, the greater the need for repair does. Thus, the order of repair or strengthening or demolition for the ten existing RC bridges in Keelung, Taiwan, is: 1. Fuh-min, 2. Guan-in, 3. Wuu-der, 4. Dong-shyh, 5. Jong-jeng, 6. Jong-san, 7. Guang-hwa, 8. Long-men, 9. Shang-ren, and 10. Jongher bridges.

The DER evaluation method was adopted to perform the synthesis evaluation arrangement with respect to the ten existing RC bridges in Keelung, Taiwan. The condition index (CI) is

$$
\mathrm{CI}=[60.70,74.53,71.78,55.19,44.73,66.25,
$$

$86.91,71.92,87.58,86.02]$
$=[$ Wuu-der, Long-men, Jong-jeng, Guan-in, Fuhmin, Dong-shyh, Shang-ren, Guang-hwa, Jong-her, Jongsan]

The repair order is: 1. Fuh-min, 2. Guan-in, 3. Wuu-der, 4. Dong-shyh, 5. Jong-jeng, 6. Jong-san, 7. Guang-hwa, 8. Long-men, 9. Shang-ren, and 10. Jongher bridges.

While the priority index $(\mathrm{PI})$ is

$\mathrm{PI}=[60.70,74.53,65.15,48.09,47.73,62.78,83$. $75,63.78,78.78,78.87]$

$=[$ Wuu-der, Long-men, Jong-jeng, Guan-in, Fuhmin, Dong-shyh, Shang-ren, Guang-hwa, Jong-her, Jongsan]

The repair order is: 1. Fuh-min, 2. Guan-in, 3. Wuu-der, 4. Dong-shyh, 5. Guang-hwa, 6. Jong-jeng, 7. Long-men, 8. Jong-her, 9. Jong-san, and 10. Shang-ren bridges.

\section{DISCUSSION}

To show the advantages and characteristics of both the comparison matrix and DER evaluation methods, we changed the weight for each bridge item to carry out the synthesis evaluation arrangement for the ten existing RC bridges stated above.

Case I: The comparison matrix method was adopted to calculate the weight for each bridge item as shown in Table 8. Through the analysis of comparison matrix method, we obtain that the repair order is: 1. Fuh-min, 2. Guan-in, 3. Wuu-der, 4. Dong-shyh, 5. Jong-jeng, 6. Jong-san, 7. Guang-hwa, 8. Long-men, 9. Shang-ren, and 10. Jong-her bridges. It is found that the predicted results are the same as the previous results as shown in the illustrative example used both the proposed and DER evaluation methods. This expresses that the weight vector evaluated by bridge expert is stable and 
Table 9. Weight for each item of bridge in D.E.R evaluation criterion (Case II)

\begin{tabular}{|c|c|c|c|c|c|}
\hline Item & Weight & Item & Weight & Item & Weight \\
\hline Substructure protection & 6 & Minor element & & Abutment $\left(\mathrm{C}_{6}\right)$ & 3 \\
\hline$\left(\mathrm{C}_{12}\right)$ & & $($ diaphragm $)\left(\mathrm{C}_{19}\right)$ & 7 & Wing masonry/ & \\
\hline Pier foundation $\left(\mathrm{C}_{13}\right)$ & 8 & Deck or hinged plate $\left(\mathrm{C}_{20}\right)$ & 8 & retaining wall $\left(\mathrm{C}_{7}\right)$ & 6 \\
\hline Pier shaft $\left(\mathrm{C}_{14}\right)$ & 8 & Guide passage $\left(\mathrm{C}_{1}\right)$ & 3 & Friction layer $\left(\mathrm{C}_{8}\right)$ & 3 \\
\hline Supporting mat $\left(\mathrm{C}_{15}\right)$ & 6 & Road embankment & & Drainage appliance $\left(\mathrm{C}_{9}\right)$ & 4 \\
\hline Shear key/ & & Guide passage $\left(\mathrm{C}_{2}\right)$ & 2 & Curb and pedestrian & \\
\hline Restrained cable $\left(\mathrm{C}_{16}\right)$ & 5 & Protection fence & & Way $\left(\mathrm{C}_{10}\right)$ & 3 \\
\hline Expansion joint $\left(\mathrm{C}_{17}\right)$ & 6 & River channel $\left(\mathrm{C}_{3}\right)$ & 5 & Balustrade/ & \\
\hline Major element (girder) & 4 & Guide passage $\left(\mathrm{C}_{4}\right)$ & 3 & Protection fence $\left(\mathrm{C}_{11}\right)$ & 3 \\
\hline \multirow[t]{2}{*}{$\left(\mathrm{C}_{18}\right)$} & & road embankment protection & & Other $\left(\mathrm{C}_{21}\right)$ & 1 \\
\hline & & Abutment foundation $\left(\mathrm{C}_{5}\right)$ & 7 & & \\
\hline
\end{tabular}

reasonable. The weight represents the relative importance between each index. It is not only a measurement but also a random and fuzzy number. In the practical problem, owing to both the internal intension of each index are different and the taken weight value maybe quite different, we can not perform comparison. Accordingly, the aim of weight value standardization is for changing the weight values in the range of 0 and 1 . The weight value of each index can be changed with different values. However, the predicted results should be of consistency. This means that the weight values are allowable variation in a range. Certainly, the variation of weight values can not influence the final actual repair order.

Case II: With respect to the important influence of weight allocation, the weight allocation is enough changed the predicted repair order. Let the weight values be changed in a small quantity as indicated in Table 9. Using the comparison matrix method to perform the optimum ordering for the ten existing $\mathrm{RC}$ bridges, we have

$$
\bar{B}=\left[\begin{array}{llllll}
0.275 & 0.142 & 0.208 & 0.293 & 0.362 & 0.238
\end{array}\right.
$$

$\left.\begin{array}{llll}0.099 & 0.132 & 0.125 & 0.167\end{array}\right]$

$=[$ Wuu-der, Long-men, Jong-jeng, Guan-in, Fuhmin, Dong-shyh, Shang-ren, Guang-hwa, Jong-her, Jongsan]

The repair order is: 1. Fuh-min, 2. Guan-in, 3. Wuu-der, 4. Dong-shyh, 5. Jong-jeng, 6. Jong-san, 7. Long-men, 8. Guang-hwa, 9. Jong-her, and 10. Shangren bridges.

If the DER evaluation method is adopted to predict the ten existing $\mathrm{RC}$ bridges, the $\mathrm{CI}$ is:

$\mathrm{CI}=[66.29,71.12,71.78,59.47,51.28,65.89$, 87.43, 68.07, 86.76, 85.01]

$=[$ Wuu-der, Long-men, Jong-jeng, Guan-in, Fuhmin, Dong-shyh, Shang-ren, Guang-hwa, Jong-her, Jong- san].

The repair order is 1. Fuh-min, 2. Guan-in, 3. Dong-shyh, 4. Wuu-der, 5. Guang-hwa, 6. Long-men, 7. Jong-jeng, 8. Jong-san, 9. Jong-her, and 10. Shang-ren bridges.

The PI is:

$\mathrm{PI}=[66.29,71.12,64.20,52.76,51.28,61.55$, $83.94,56.88,78.69,74.12]$

$=[$ Wuu-der, Long-men, Jong-jeng, Guan-in, Fuhmin, Dong-shyh, Shang-ren, Guang-hwa, Jong-her, Jongsan].

The repair order is: 1. Fuh-min, 2. Guan-in, 3. Guang-hwa, 4. Dong-shyh, 5. Wuu-der, 6. Long-men, 7. Jong-jeng, 8. Jong-san, 9. Jong-her, and 10. Shang-ren bridges.

Case III: Let the weight values vary as indicated in Table 10. Using the comparison matrix method to perform the optimum ranking for the ten existing $\mathrm{RC}$ bridges, we obtain

$$
\bar{B}=\left[\begin{array}{llllll}
0.234 & 0.171 & 0.251 & 0.256 & 0.334 & 0.233
\end{array}\right.
$$
$\left.\begin{array}{llll}0.212 & 0.157 & 0.127 & 0.095\end{array}\right]$

$=[$ Wuu-der, Long-men, Jong-jeng, Guan-in, Fuhmin, Dong-shyh, Shang-ren, Guang-hwa, Jong-her, Jongsan].

The repair order is: 1. Fuh-min, 2. Guan-in, 3. Jong-jeng, 4. Wuu-der, 5. Dong-shyh, 6. Shang-ren 7. Long-men, 8. Guang-hwa, 9. Jong-her, and 10. Jong-san bridges.

If the DER evaluation method is employed to assess the ten existing $\mathrm{RC}$ bridges, the $\mathrm{CI}$ is

$\mathrm{CI}=(68.33,69.79,69.70,60.29,52.98,67.59$, $87.16,53.80,88.26,87.84)$

$=($ Wuu-der, Long-men, Jong-jeng, Guan-in, Fuhmin, Dong-shyh, Shang-ren, Guang-hwa, Jong-her, Jongsan). 
Table 10. Weight for each item of bridge in D.E.R evaluation criterion (Case III)

\begin{tabular}{|c|c|c|c|c|c|}
\hline Item & Weight & Item & Weight & Item & Weight \\
\hline Substructure protection $\left(\mathrm{C}_{12}\right)$ & 6 & Minor element & & Abutment $\left(\mathrm{C}_{6}\right)$ & 3 \\
\hline Pier foundation $\left(\mathrm{C}_{13}\right)$ & 8 & $($ diaphragm $)\left(\mathrm{C}_{19}\right)$ & 9 & Wing masonry/ & \\
\hline Pier shaft $\left(\mathrm{C}_{14}\right)$ & 3 & Deck or hinged plate $\left(\mathrm{C}_{20}\right)$ & 9 & retaining wall $\left(\mathrm{C}_{7}\right)$ & 2 \\
\hline Supporting mat $\left(\mathrm{C}_{15}\right)$ & 8 & Guide passage $\left(\mathrm{C}_{1}\right)$ & 3 & Friction layer $\left(\mathrm{C}_{8}\right)$ & 3 \\
\hline Shear key/ & & Road embankment & & & \\
\hline Restrained cable $\left(\mathrm{C}_{16}\right)$ & 5 & Guide passage $\left(\mathrm{C}_{2}\right)$ & 2 & Drainage appliance $\left(\mathrm{C}_{9}\right)$ & 7 \\
\hline Expansion joint $\left(\mathrm{C}_{17}\right)$ & 6 & Protection fence & & Curb and pedestrian & \\
\hline \multirow[t]{4}{*}{ Major element(girder) $\left(\mathrm{C}_{18}\right)$} & 4 & River channel $\left(\mathrm{C}_{3}\right)$ & 7 & Way $\left(\mathrm{C}_{10}\right)$ & 2 \\
\hline & & Guide passage $\left(\mathrm{C}_{4}\right)$ & 3 & Balustrade/ & \\
\hline & & road embankment protection & & Protection fence $\left(\mathrm{C}_{11}\right)$ & 3 \\
\hline & & Abutment foundation $\left(\mathrm{C}_{5}\right)$ & 7 & Other $\left(\mathrm{C}_{21}\right)$ & 1 \\
\hline
\end{tabular}

The repair order is: 1. Fuh-min, 2. Guang-hwa, 3. Guan-in, 4. Dong-shyh, 5. Wuu-der, 6. Jong-jeng, 7. Long-men, 8. Shang-ren, 9. Jong-san, and 10. Jong-her bridges.

\section{The PI is}

$\mathrm{PI}=(68.33,69.79,61.17,52.34,52.98,62.50$, $82.33,40.80,80.31,86.33)$

$=($ Wuu-der, Long-men, Jong-jeng, Guan-in, Fuhmin, Dong-shyh, Shang-ren, Guang-hwa, Jong-her, Jongsan).

The repair order is: 1. Guang-hwa, 2. Guan-in, 3. Fuh-min, 4. Jong-jeng, 5. Dong-shyh, 6. Wuu-der, 7. Long-men, 8. Jong-her, 9. Shang-ren, and 10. Jong-san bridges.

It is obvious that the change of weight allocation should be altered the synthesis evaluation repair order.

Case IV: Assume that the Dong-shyh, Long-men, Jong-her, and Shang-ren bridges are important. The estimation index for these four bridges were obtained from the product of each DER value (i. e., $D \times E \times R^{2}$ ) whereas the estimation index for the other six bridges were obtained from the product of each DER value (i.e., $D \times E \times R)$ as shown in Table 11. Both the analytical and calculated methods are similar to the illustrative example. Therefore, we have the results as shown in the following:

$\bar{B}=\left[\begin{array}{llllll}0.171 & 0.170 & 0.142 & 0.165 & 0.213 & 0.395\end{array}\right.$ $\left.\begin{array}{llll}0.162 & 0.072 & 0.125 & 0.107\end{array}\right]$

$=[$ Wuu-der, Long-men, Jong-jeng, Guan-in, Fuhmin, Dong-shyh, Shang-ren, Guang-hwa, Jong-her, Jongsan]

and the repair order: 1. Dong-shyh, 2. Fuh-min, 3. Wuuder, 4. Long-men, 5. Guan-in, 6. Jong-jeng, 7. Shangren, 8. Jong-san, 9. Jong-her, and 10. Gauan-hwa bridges. $\mathrm{CI}=[90.16,77.58,92.95,89.64,86.93,70.87$, 91.69, 92.98, 91.59, 96.50]

$=[$ Wuu-der, Long-men, Jong-jeng, Guan-in, Fuhmin, Dong-shyh, Shang-ren, Guang-hwa, Jong-her, Jongsan]

and the repair order: 1. Dong-shyh, 2. Long-men, 3.
Fuh-min, 4. Guan-in, 5. Wuu-der, 6. Jong-her, 7. Shangren, 8. Jong-jeng, 9. Guang-hwa, and 10. Jong-san bridges.

$\mathrm{PI}=(90.16,77.58,92.95,87.02,86.93,66.69$, $85.44,90.95,84.09,97.64)$

$=($ Wuu-der, Long-men, Jong-jeng, Guan-in, Fuhmin, Dong-shyh, Shang-ren, Guang-hwa, Jong-her, Jongsan)

and the repair order: 1. Dong-shyh, 2. Long-men, 3. Jong-her, 4. Shang-ren, 5. Fuh-min, 6. Guan-in, 7. Wuuder, 8. Guang-hwa, 9. Jong-jeng, and 10. Jong-san bridges.

If compare the weights for each item of bridge listed in Tables 2, 8 (Case I) and 9 (Case II), then it is obvious that the weight variation range of Case II is larger than that of Case I. If compare the evaluated results obtained from the comparison matrix method with DER evaluation method then the ranking variation of Case II is again larger than that of Case I. Considering the former five bridges for urgent repair, four bridges have the same results. The most severe bridge is the same as the Fuh-min bridge. It is clearly seen that the repair order evaluated by the DER method is reasonable and feasible. For the Case II, two of former three urgent repair bridges are different between the proposed and DER methods. Accordingly, the evaluated results will be different under different weight allocations. Since the weight allocation is not unique, the estimation factor weight is generally allowed variation in a range. Wang and Chang [26] pointed out that if the weight allocation is varied within $10 \%$ then the evaluated result is still unchanged. The evaluated result is available under the allowable variation range of estimation factor weight while the evaluated result is not reliable over the allowable variation range of estimation factor weight. With respect to Case IV, the urgent repair is the Dong-shyh bridge which is different to the Fuh-min bridge obtained from both the proposed and DER evaluation methods in Case III. Accordingly, the evaluator would be careful 
Table 11. Bridge system estimation criterion and index

\begin{tabular}{|c|c|c|c|c|c|c|c|c|c|c|c|c|c|}
\hline \multirow{2}{*}{$\begin{array}{l}\text { Estimation } \\
\text { criterion }\end{array}$} & \multirow{2}{*}{ Subsystem } & \multirow[t]{2}{*}{ Estimation item } & \multirow{2}{*}{$\begin{array}{l}\text { Estimation } \\
\text { item } \\
\text { Weight }\end{array}$} & \multicolumn{10}{|c|}{ Bridge estimation index } \\
\hline & & & & Wuu-der & Long-men & Jong-jeng & Guan-in & Fuh-min & Dong-shyh & Shang-ren & Guang-hwa & Jong-her & Jong-san \\
\hline \multirow{11}{*}{$\begin{array}{l}\text { General } \\
\text { assessment } \\
\text { items }\end{array}$} & \multirow{11}{*}{0.25} & Guide Passage, road embankment & 0.0698 & $\mathrm{x}$ & $\mathrm{x}$ & $\mathrm{x}$ & $\mathrm{x}$ & $\mathrm{x}$ & $\mathrm{x}$ & $\mathrm{x}$ & $\mathrm{x}$ & $\mathrm{x}$ & $\mathrm{x}$ \\
\hline & & Guide Passage, protection fence & 0.0464 & 0 & 0 & 0 & 0 & 0 & 92 & 0 & 0 & 0 & 0 \\
\hline & & River channel & 0.093 & 0 & 0 & 0 & 18 & 0 & 0 & 24 & 0 & 2 & 0 \\
\hline & & Guide passage, road, embankment protection & 0.0698 & 0 & 0 & 0 & 0 & 0 & 0 & 0 & 0 & 0 & 18 \\
\hline & & Abutment foundation & 0.1628 & $\mathrm{x}$ & $\mathrm{x}$ & $\mathrm{x}$ & $\mathrm{x}$ & $\mathrm{x}$ & $\mathrm{x}$ & $\mathrm{x}$ & $\mathrm{x}$ & $\mathrm{x}$ & $\mathrm{x}$ \\
\hline & & Wing masonry & 0.1163 & 0 & 0 & 0 & 0 & 0 & 0 & 24 & 3 & 2 & 12 \\
\hline & & Friction layer & 0.0698 & $\mathrm{x}$ & $\mathrm{x}$ & $\mathrm{x}$ & $\mathrm{x}$ & $\mathrm{x}$ & $\mathrm{x}$ & $\mathrm{x}$ & $\mathrm{x}$ & $\mathrm{x}$ & $\mathrm{x}$ \\
\hline & & Drainage appliance & 0.093 & 0 & 0 & 0 & 0 & 0 & 0 & 0 & 0 & 2 & 0 \\
\hline & & Curb and Pedestrian way & 0.0465 & 0 & 0 & 0 & 0 & 0 & 0 & 0 & 16 & 0 & 0 \\
\hline & & Balustrade Protection fence & 0.0698 & $\mathrm{x}$ & $\mathrm{x}$ & $\mathrm{x}$ & $\mathrm{x}$ & $\mathrm{x}$ & $\mathrm{x}$ & $\mathrm{x}$ & $\mathrm{x}$ & $\mathrm{x}$ & $\mathrm{x}$ \\
\hline & & Other & 0.0233 & $\mathrm{x}$ & $\mathrm{x}$ & $\mathrm{x}$ & $\mathrm{x}$ & $\mathrm{x}$ & $\mathrm{x}$ & $\mathrm{x}$ & $\mathrm{x}$ & $\mathrm{x}$ & $\mathrm{x}$ \\
\hline \multirow{8}{*}{$\begin{array}{l}\text { Detail } \\
\text { assessment } \\
\text { items }\end{array}$} & \multirow{8}{*}{0.75} & Substructure protection & 0.1036 & $\mathrm{x}$ & $\mathrm{x}$ & $\mathrm{x}$ & $\mathrm{x}$ & $\mathrm{x}$ & $\mathrm{x}$ & $\mathrm{x}$ & $\mathrm{x}$ & $\mathrm{x}$ & $\mathrm{x}$ \\
\hline & & Pier foundation & 0.1379 & $\mathrm{x}$ & $\mathrm{x}$ & $\mathrm{x}$ & $\mathrm{x}$ & $\mathrm{x}$ & $\mathrm{x}$ & $\mathrm{x}$ & $\mathrm{x}$ & $\mathrm{x}$ & $\mathrm{x}$ \\
\hline & & Pier shaft & 0.1207 & 27 & 36 & 12 & 27 & 36 & 96 & 2 & 2 & 54 & 36 \\
\hline & & Prevention earthquake block & 0.0862 & $\mathrm{x}$ & $\mathrm{x}$ & $\mathrm{x}$ & $\mathrm{x}$ & $\mathrm{x}$ & $\mathrm{x}$ & $\mathrm{x}$ & $\mathrm{x}$ & $\mathrm{x}$ & $\mathrm{x}$ \\
\hline & & Expansion joint & 0.1034 & $\mathrm{x}$ & $\mathrm{x}$ & $\mathrm{x}$ & $\mathrm{x}$ & $\mathrm{x}$ & $\mathrm{x}$ & $\mathrm{x}$ & $\mathrm{x}$ & $\mathrm{x}$ & $\mathrm{x}$ \\
\hline & & Major member & 0.1379 & 48 & 2 & 18 & 48 & 48 & 54 & 0 & 6 & 0 & 2 \\
\hline & & Minor member & 0.1034 & 18 & 2 & 36 & 0 & 27 & 16 & 2 & 0 & 0 & 4 \\
\hline & & Deck & 0.1207 & 2 & 192 & 36 & 27 & 18 & 192 & 128 & 64 & 18 & 0 \\
\hline
\end{tabular}

Table 12. Bridge system hierarchy process, weight and membership degree

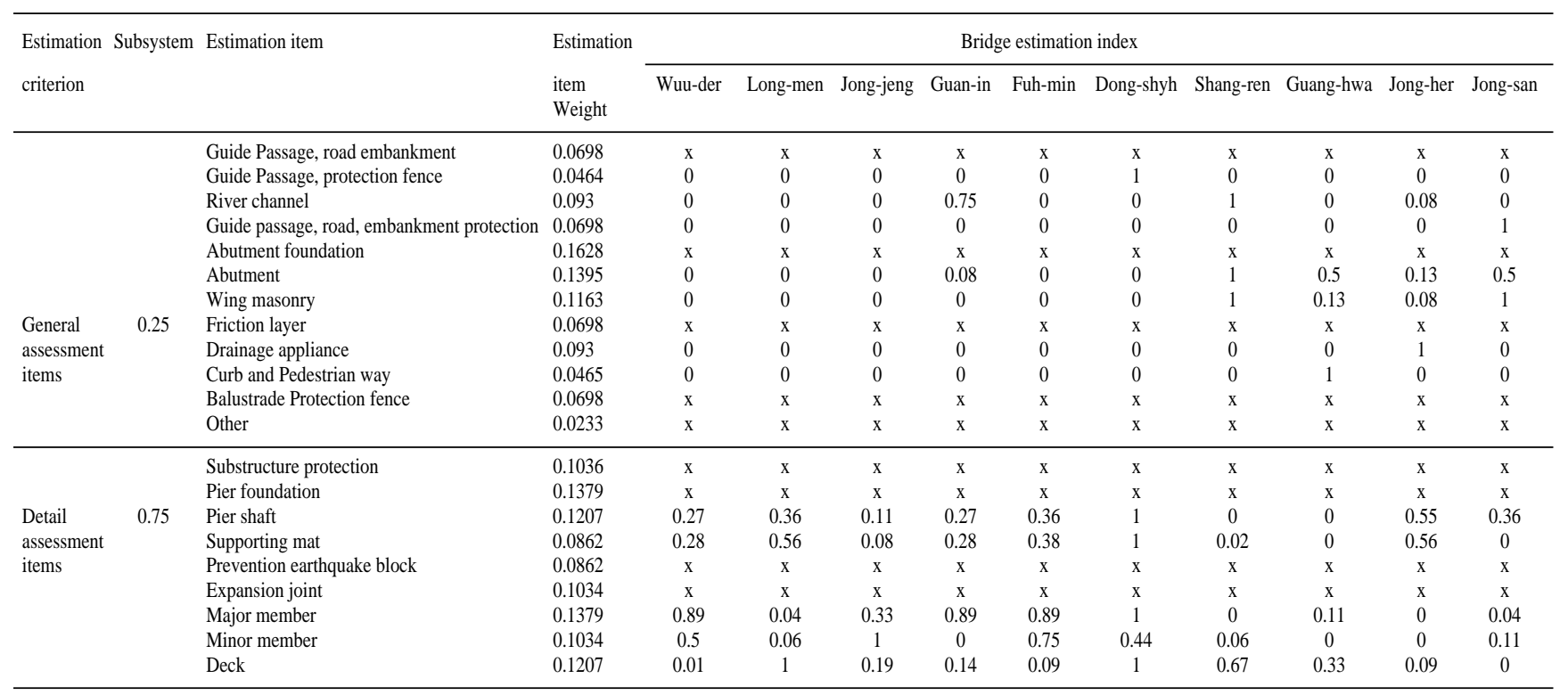

how to determine which one bridge is important, otherwise the evaluated result is meaningless.

\section{CONCLUSIONS}

Both the comparison matrix and DER evaluation methods have been described. They were adopted to evaluate the repair order of the ten existing RC bridges in Keelung, Taiwan. The evaluated repair order results obtained from both the proposed and DER evaluation methods are the same as follows: 1. Fuh-min, 2. Guanin, 3. Wuu-der, 4. Dong-shyh, 5. Jong-jeng, 6. Jong-san, 7. Guang-hwa, 8. Long-men, 9. Shang-ren, and 10. Jong-her bridges. Since the weight allocation is not unique, the estimation factor weight is generally allowable variation in a range. If the weight allocation is varied within $10 \%$ then the evaluated result is unchanged. It is worthy to point out that the repair order predicted by the DER evaluation method is very reasonable and acceptable. 
The comparison matrix method through the relative weight between layered construction factors is good in agreement with the consistence requirement of comparison judgment. The calculated results of illustrative example indicate that the proposed method is full of efficiency. This proposed method is also simple and practical. The proposed method appears to be a useful and powerful method in predicting the repair order for existing RC bridges.

\section{ACKNOWLEDGMENTS}

The authors would like to thank the Join Engineering Consultants for its financial support of this study.

\section{REFERENCES}

1. Benedetto, J.J. and Frazier, N.W., eds.,"Wavelets, Mathematics and Applications”, CRC, Boca Raton, Fla. (1993).

2. Bungey, J.H., "Assessment of Concrete in Bridge Structures," Concrete Bridge Engineering: Performance and Advances, R. J. Cope, Ed., Elsevier Applied Science, New York, N. Y., pp. 25-62 ( 1987).

3. Chang, F.K., ed., "Structural Health Monitoring: Current Status and Perspectives," Proceeding of the International Workshop on Structural Health Monitoring, Stanford University, Stanford, CA., Sept. 18-20 (1997).

4. Chen, J., "Structured Comparison Matrix Method and Fuzzy Hierarchy Synthetic Evaluation," J. Chengdu University Sci. Technol., No. 3, pp. 81-86 (1989) (in Chinese).

5. Chui, C.K., Introduction to Wavelets, Academic, San Diego, CA. (1992).

6. CSIR, "Taiwan Area National Freeway Bureau Bridge Management System: Description of Modulues and Computer Options," PO Box 395, Pretoria, South Africa, pp. 47 (1994).

7. Doelling, S.W., Farrar, C.R., Prime, M.B., and Shevity, D.W., "Damage Identification and Health Monitoring of Structural and Mechanical Systems from Changes in Their Vibration Characteristics: A Literature Review," Report LA-13070-MS, Los Alamos National Laboratory, Los Alamos, N.M. (1996).

8. Essaway, M.A., Diwaker, S., Zein-Sabatto, S., and Garge, A.K., "Fault Diagnosis of Helicopter Gearboxes Using Neuro-fuzzy Techniques," Proceedings of 52nd Meeting of the Society for Machinery Failure Prevention Techniques: Prognosis of Residual Life of Machinery and Structure, Haymarket, Va., pp. 293-302 (1998).

9. Frangopol, D.M. and Hearn, G. eds., Structural Reliability in Bridge Engineering: Design, Inspection, Assessment, Rehabilitation and Management, McGrawHill Book Co., Inc., New York, N. Y. (1996).

10. Frangopol, D.M., Lin, K.-Y., and Ester, A.C., "Reliabil- ity of Reinforced Concrete Girders under Corrosion Attack," J. Struct. Engine., Vo1. 123, No. 3. ASCE, pp. 286-297 (1997).

11. Hou, Z., Noori, M., and Amand, R.St., "Wavelet-based Approach for Structural Damage Detection," J. Engin. Mechanics, Vol. 126, No. 7, ASCE, pp. 677-683 (2000).

12. Join Engineering Consultants, Report on the Detection Engineering of Bridge in Keelung City (2000).

13. Li, Q.F., Zhao, G.F., Liang, M.T., and Chang, J.W., "Durability Damage Grey Analyzing the Concrete Carbonation,” J. Grey Sys., Vol. 13, No.1, pp. 88-94 (2001).

14. Liang, M.T., Wu, J.H. and Liang, C.H., “Applying Fuzzy Mathematics to Evaluating the Membership of Existing Reinforced Concrete Bridges in Taipei," J. Marine Sci. Technol., Vol. 8, No. 1, pp. 16-29 (2000).

15. Liang, M.T., Wu, J.H., and Liang, C.H., "Multiple Layer Fuzzy Evaluation for Existing Reinforced Concrete Bridges," J. Infrast. Syst., Vol. 7, No. 4, ASCE, pp. 144159 (2001a).

16. Liang, M.T., Wang, H.D., and Wu, J.H., "Multiple Objective and Span Evaluation Method for Damage Grade of Existing Reinforced Concrete Bridges," $J$. Marine Sci. Technol., Vol. 9, No. 2, pp.133-144 (2001b).

17. Liang, M.T., Zhao, G.F., Chang, C.W., and Liang, C.H., "Evaluating Carbonation Damage to Condrete Bridge Using a Grey Forecasting Model Improvement Combined with a Statistical Method," J. Chinese Inst. Engin., Vol. 24, No. 1, pp. 85-94 (2001c).

18. Liang, M.T., Chang, J.W., and Li, Q. F., "Grey and Regression Models Predicting the Remaining Service Life of Existing Reinforced Concrete Bridges," J. Grey Syst., Vol. 14, No. 4, pp. 291-310 (2002b).

19. Lin, A.Y., "Freeway Bridge Management System," Civil Engin. Techniques, Vol. 2, No. 2, pp. 97-110 (1998) (in Chinese).

20. Middleton, C., and Low, A., "The Use of Reliability Analysis in the Assessment of Existing Bridges," Bridge Management: Inspection, Maintenance and Repair, J.E. Harding et al. ed., Elsevier, London, pp. 417-428 (1990).

21. Saaty, T.L., The Analytic Hierarchy Process: Planning, Priority Setting, Resource Allocation, McGraw-Hill International Book Company, New York (1980).

22. Thoft-Christensen, P., "Advanced Bridge Management System,” Struct. Engin. Rev., Vol. 7, No. 3, pp. 151-163 (1995).

23. Tsou, P., and Shen, M.H.H., "Structural Damage Detection and Identification Using Neural Networks," AIAA J., Vol. 32, No. 1, pp. 176-183 (1994).

24. Val, D.V., and Melchers , R.E., "Reliability of Deteriorating RC Slab Bridges," Journal of Structural Engineering, Vol. 123, No. 12, ASCE, pp. 1638-1644 (1997).

25. Vanik, M.W., and Beck, J. L., “A Bayesian Probabilistic 
Approach to Structural Health Monitoring," Proceedings of International Workshop on Structural Health Monitoring: Current Status and Perspectives, Stanford University, Stanford, California, pp. 140-151 (1997).

26. Wang, F. and Chang, Y., "A Study of Weight and Determing the Weight Allocation Method," Syst. Engin., Vol. 11, No. 5, pp. 11-14 (1993) (in Chinese).

27. Wu, X., Ghabossi, J., and Garrett, J.H., "Use of Neural Networks in Detection of Structural Damage," Computer Struct., Vol. 42, No. 4, pp. 649-659 (1992).

28. Yang, G., "Finding the Weight and Ranking of Multiple
Objectives Using Comparison Matrix Method," Syst. Engin. Theory Pract., No. 1, pp. 19-26 (1998) (in Chinese ).

29. Yu, L. and Cheng, M., "A New Method to Group Decision-Making with Multiple Objectives-Interactive Comparison Matrice Approach," J. Syst. Engin., Vol. 9, No. 2, pp. 28-35 (1994) (in Chinese).

30. Zadeh, L.A., "Outline of a New Approach to the Analysis of Complex Systems and Decision Processes," IEEE Trans. Syst., Vol. 3, pp. 28-44 (1973). 